\title{
LA REHABILITACION DE LOS PACIENTES AFASICOS
}

\author{
Jorge Gonzalez Cruchaga *
}

El problema, tema de esta conferencia, fué planteado por vez primera en 1904 por Charles Mills quien publicó en J.A.M.A. un artículo titulado "Treatment of aphasia by training". Las opiniones sobre el problema siguen en debate a pesar de haber transcurrido casi 70 años desde que se abrió inicialmente la problemática. Esta indefinición depende, a mi entender, del hecho de que en lo que a afasia se refiere hay un gran porcentaje de subjetivismo que corresponde a los prejuicios que sobre el tema se tenga: para esclarecer a los que me escuchan creo conveniente el expresar lo más claramente posible cuales son mis propios prejuicios. $\mathrm{Y}$ para ello me parece practico el repetir la definición de Afasia que he elaborado y publicado en otras ocasiones (Gonzalez C., JoRge - El Síndrome Afásico. Editorial Andres Bello, Santiago de Chile, 1969): para mí la Afasia es "un sindrome caracterizado esencialmente por una asimbolía adquirida del código verbal y escrito y o un trastorno articulatorio motor de origen encefálico habitualmente focal y que cursa en un cuadro orgánico cerebral". No es una definición que pretenda ser original pero expresa mi acuerdo con los conceptos de la tendencia holística funcional.

La importancia de la reeducación es evidente para cualquire que tenga experiencia en Clínica Neurologica y la presión que los pacientes y sus familiares desarrollan para obtener una terapia racional es algo que llega tanto al medico general como al especialista. En múltiples ocaciones hemos comprobado que si el médico no toma la delantera en la indicación de alguna forma de terapia, los familiares inician la tarea en forma intuitiva y primitiva.

Existe en algunos círculos neurológicos una idea pesimista y negativa acerca del tema. Se dice que se recuperará aquel paciente que tenga un mecanismo residual de lenguaje capaz de desarrollar su función y que los intentos terapéuticos son inútiles ya que se trata de una función psiquica sobre la cual poco se puede actuar. Esto mismo ha sido expresado gráficamente en aquel dicho que sostiene que "así como el hemiplégico queda cojo, también la palabra queda claudicante". Nuestra experiencia recogida a travez de cinco años de rehabilitación del lenguaje en nuestro Servicio de Neurologia no está de acuerdo con esta idea negativista aunque, como detalla-

* Professor Extraordinario de Neurologia. Universidad de Chile (Hospital Salvador, Santiago de Chile). Comunicacion al IV Congreso de la Academia Brasileira de Neurologia (Porto Alegre, 5-9 de Julho, 1970). 
remos más adelante, somos muy cautos en indicar terapia foniátrica a fondo y reconocemos el que aún en los mejores casos el cuadro psico-orgánico basal es algo que queda más allá de las posibilidades de acción.

Mecanismos de mejoría del lenguaje en los lesionados cerebrales - Debemos aceptar el que si poco se sabe sobre como mejoran los defectos motores de los hemiplégicos, menos se conoce aún acerca del porqué de la recuperación del lenguaje. Habrían tres mecanismos básicos a saber:

1) Reducción lesional - En los primeros dias que siguen a un importante porcentaje de lesiones cerebrales se asiste a una reducción espontánea del tamaño lesional. Disminuye el edema, mejora la circulación de las regiones vecinas, retrocede la diasquisis aumentando la conductibilidad del sistema nervioso y recuperando su normalidad la transmición sináptica. El grado de esta reducción lesional depende de la edad del paciente, la etiología, el tiempo transcurrido, la dominancia cerebral y la intensidad del cuadro psico-orgánico acompanante del trastorno afásico. Por cierto que este mecanismo está présente en muchos de nuestros casos.

2) Reorganización de la función cerebral - El defecto afásico mejoraria cuando estructuras neurales no lesionadas tomaran a su cargo la función del lenguaje. Foerster fué el iníciador de esta teoria que coincidió con la posición de Hughlings Jackson quién al sostener el caracter de "leader" del hemisferio mayor en la expresión verbal proposicional, dejaba al hemisferio derecho un rol fundamental en la emisión oral automática. El afásico mejorado se expresaría de acuerdo a estas ideas mediante la función de su hemisferio no dominante. Estas proposiciones no han sido nunca probadas y parece muy poco probable el que sustratos neurales no relacionados con el lenguaje puedan ser capaces de tomar funciones en el habla.

3) Reajuste general orgánico con aparición de conductas sustitutivas - Es Goldstein quién sostiene esta teoria, diciendo que la mejoría depende de un reajuste de todo el organismo a la nueva situación con predominio de patrones de conducta expresiva de nivel inferior. Al expresar estas ideas, Goldstein no hace sino seguir la doctrina de los niveles jacksonianos de función del neuro eje y no hay duda de que nadie podrá dejar de lado la verdad que esta postulación contiene.

Bases teoricas de una terapia del lenguaje - Hay razones neurofisiológicas que sustentan la utilidad de la rehabilitación del lenguaje, que son las mismas o muy parecidas a las que usamos los neurólogos cuando indicamos rehabilitar al deficitario motor o sensitivo. Estas bases teóricas son las siguientes:

a) Estímulo de una función deficitaria - Asi como se alienta la movilización de una extremidad paresiada, es de toda lógica el estimular el lenguaje de los lesionados del habla. Los fisioterapeutas con la aprobación general estimulan el automatismo del andar y parece lógico tener igual actitud con los afásicos.

b) Reforzamiento de los reflejos condicionados - Qualquiera con experiencia en afasia sabe de como los pacientes llegan a condicionarse reflejamente y expresarse en forma automática frente a estímulos adecuados.

c) Aprovechamiento de los automatismos latentes en el paciente y fuera de función en el sujeto normal por la dominancia de funciones superiores - 
Todos los dias se ve en los afásicos de como una serie o un recuerdo despierta posibilidades de comunicación yacentes apagadas minutos antes.

Podrá decirse que estas bases de la rehabilitación del lenguaje no pasan más allá de ser teoria, pero para quién ha vivido con afásicos estas no son especulaciones sino realidades vivas que dán lógica a nuestra conducta positiva frente al problema.

Indicaciones de la terapia de rehabilitacion - Estamos muy lejos de los que creem que toda afasia debe ser sometida a rehabilitación. Sin nombrar opiniones respetables, creemos un absurdo aquello de que todos los afasicos deben ser sometidos a una terapia de prueba de seis semanas antes de decidir si debe continuarse con su terapia o dejarlos abandonados a su suerte. Un neurólogo experimentado sabe con un examen habitualmente somero si el caso va a rendir o si es mejor no someter al paciente a ilusiones terapéuticas dañinas: también puede decidir clínicamente si se va a estimular la recuperación de la función perdida o si es más prudente entrenar al paciente en algún sistema de compensación de su defecto. Si se juzga que el circuito del lenguaje está conservado y que su alteración es solo funcional, debe indicarse su entrenamiento. A la inversa, si se piensa que el dáño neuronal es irreversible, lo prudente es tratar de compensar el defecto y no empeñarse en entrenar una función cuyo daño es irreparable. En suma al ingreso debe resolverse acerca del punto crucial: compensar o reentrenar.

Para decidir cuales son los pacientes aptos para rehabilitación es indispensable el clasificarlos y nada es mejor conocido que el caos de clasificación de los síndromes afásicos. En nuestra práctica hemos procedido con un criterio muy pragmático basado fundamentalmente en los trabajos de Weissemburg y Mac Bride y distinguimos cinco tipos fundamentales: afasia global; de predominio comprensivo; de predominio expresivo; afasia amnéstica; disartria cortical con o sin apraxia buco-lingual. En esta ordenación no pretendemos tomar partido conceptual alguno acerca de las teorias de la afasia, sino solo describir fenomenológicamente lo que se vé y escucha al examinar a los enfermos.

Cuando, pasado el período agudo, nos convencemos que se trata de una afasia global o de predominio comprensivo abandonamos toda terapia que no sea psicoterapia de apoyo y creemos que las tecnicas que detallaremos más adelante son un derroche inutil de esfuerzo médico.

Los pacientes de mejor rendimiento son los sujetos jóvenes y talentosos con afasia de predominio expresivo y buena motivación; en ellos creemos que se justifican los esfuerzos terapéuticos de larga duración.

En la afasia de predominio amnéstico es donde tenemos con frecuencia los mayores problemas: hemos visto lo mismo que Goldstein describe tan adecuadamente en sus trabajos. Los amnésticos no son enfermos de un deficit de memoria, sino sujetos afectos de una alteración de la actitud categorial en los cuales no es una mera palabra la que falta, sino la actitud abs- 
tracta necesaria para tener el concepto del fonema adecudo. Son sujetos que emiten la palabra a ratos y un momento después no pueden usarla: en ellos la repetición torturante pseudo-terapéutica de listas de sustantivos o verbos no conduce sino a martirizar al enfermo que dice palabras para olvidarlas en el acto, al igual que nosotros los normales olvidamos las palabras sin sentido que se nos hizo memorizar en una lengua extrangera.

En las disartrias corticales y apraxias buco-linguales nuestra experiencia ha sido habitualmente satisfactoria y estimamos que merecen un esfuerzo terapéutico máximo.

Si se analizan las indicaciones que hemos dado para rehabilitar, podrá comprobarse que si bién estamos de acuerdo con la necesidad de haver un avalúo inicial en todo enfermo del lenguaje, las limitaciones que hemos esbozado son tantas que para nosotros el grupo de enfermos en los cuales se justifica un esfuerzo a fondo de rehabilitación es bastante reducido.

Metodos de terapia - La rehabilitación del lenguaje es en los afásicos una forma especializada de psicoterapia y por ello la relación médico-paciente es esencial y será falsa toda aquella postulación que intente entrenar un lenguaje artificial con métodos artificiales. Esto conducirá solo a un ser humano sin alma desempeñandose en un mundo también vacio y sin alma.

Las discusiones acerca de si son superiores los métodos holísticos o analíti$\cos$ (Maruszewski) o la terapia específica versus la inespecífica o psico-linguística (M. Taylor) no pasan más allá de ser ideas de ordenación formal ante el problema y están destinadas a promover bases de discusión académica. Todos los que trabajan en afasia están de acuerdo en que la terapia es algo absolutamente individual adaptada a cada caso particular y realizada por un equipo de neurólogos, psicólogos y foniatras, entre los cuales debe existir una intercomunicación amplia y donde la palabra definitiva pertenece al clínico neurólogo. Es absurdo el dar "recetas" para tratar afásicos: discusiones amplias y detalladas de lo que puede hacerse se encuentran en los textos de Agranawitch, Wepman, West, Hildred Schuel, Longerich, Alajouanine, Van Riper y Goldstein. En nuestro Servicio hemos adaptado a la realidad linguístico-cultural de los pacientes esquemas de articulación, nominación, sintaxis, lectura, escritura, cálculo, dibujo, actividades plásticas y estimulo general multisensorial del lenguaje. La terapia es más un arte que una ciencia y en ella se procede por ensayo y error, intuyendo e improvisando a medida que el caso evoluciona.

Debe iniciarse la rehabilitación tan pronto como sea posible o sea que es indispensable el que se halla esclarecido la conciencia, tan frecuentemente oscura en los casos iniciales de afasia. No creemos que sea oportuna la idea de Rusk que propicia el comienzo de la terapia a las 48 horas de iniciada la enfermedad y estimamos demasiado conservadora la posición de Hildred Schuell que además de conciencia clara exige el que los pacientes sean capaces de mantenerse sentados durante dos horas sin fatiga para comenzar a tratarlos. 
En los casos de afasia expresiva hemos mantenido pacientes en entrenamiento hasta durante dos años, aunque creemos que en esta materia rige la regla general de la medicina de rehabilitación que hace continuar el tratamiento hasta que se demuestre que se ha detenido la mejoría.

No creemos en la terapia de grupo de los afásicos, ya que con gran frecuencia esto no es más que un ritual comunitario que puede ser pernicioso al poner en contacto afásicos de diferente gravedad y nivel socio-cultural con resultados depresivos para algunos de los miembros del grupo. El canto coral entre afásicos que algunos textos preconizan con entusiasmo no lo hemos visto llevar sino a fustraciones y a patéticas situaciones. La única ventaja de la terapia grupal sería la de avitar el aislamiento, ya que es bién conocida la trágica fuga de amistades que sufre tanto el afásico como el que se hace ciego o sordo. Creo sin embargo que los grupos de afásicos alentados a reunirse con el objeto de crear amistades no cumplen sus objetivos ya que todo ser humano gusta de seleccionar a sus amistades $y$, a mi modo de ver, es pueril el pretender que un afásico va a escoger a alguién de su misma condición como amigo.

Resultados de la terapia - Existe el antiguo debate entre los que creen en la eficiencia específica de la rehabilitación, aquellos que solo creen en la mejoría dependiente de la recuperación espontánea de la lesión y los que sostienen que solo estamos frente a una variedad de psicoterapia de apoyo que a veces degenera en manos bién intencionadas pero inhábiles en pura filantropía. No se ha logrado obtener series comparables de sujetos tratados y controles a fín de establecer la validez estadística de la terapia y no van a lograrse nunca series de este tipo dada la enorme cantidad de variables que el problema presenta. La situación no será nunca zanjada por la vía matemática, además de que todo afasiólogo sabe perfectamente como es de dificil el intento de cuantificar un defecto de lenguaje ya que la capacidad de expresión varía sin cesar y un paciente es capaz de pronunciar, en un momento, una palabra larga y dificil o una frase correcta para fracasar, a continuación, en una palabra corta y sencilla desde el punto de vista motor.

Nuestra experiencia habiendo atendido más de 300 afásicos en los últimos cinco años es bastante definida. En lo negativo tenemos el que evidentemente no hay justificación económica para el esfuerzo que la rehabilitación supone y el que a mayor nivel intelectual del paciente más insatisfactorios son los resultados. Pero frente a estos aspectos negativos hemos tenido casos en los cuales nos ha parecido que la terapia ha sido de enorme utilidad: es la impresión no cuantificada ni cuantificable de un clínico, pero creemos firmemente que es valedera. Y esta impresión está avalada por la opinión unánime de personalidades de tanto peso como Russell Brain, Granich, Weissemburg, Alajouanine y Goldstein entre los neurólogos. Este último patrocina la rehabilitación del lenguaje aún en aquellos casos en los que las posibilidades de recuperación espontáneo son elevadas, sosteniendo el que con frecuencia el paciente no es capaz por si solo de realizar el esfurzo de iniciar su curación. Despues de haber tratado muchos heridos de guerra dice tex- 
tualmente Goldstein "incluso después de tener que rendir-se a la evidencia de los buenos resultados que obtienen con el tratamiento este no se ha convertido en un método de aceptación general."

Lo que a veces desacredita la terapia es el hecho de que ha sido abandonada con frecuencia por los neurólogos en manos de personal de entrenamiento deficiente, habitualmente paramédico que, con conocimientos sumarios sobre las funciones superiores del cerebro, se apoderan del paciente sometiéndolo a ejercicios sin futuro. El equipo de trabajo es indispensable, pero solo obtendrá exitos aquel neurólogo que seleccione cuidadosamente los casos a tratar y que sea el personalmente el que guie paso a paso a su enfermo.

Avenida El Bosque 576 - Santiago - Chile. 